\title{
Consultoria Interna: inspirando-se em Argyris para uma ação mais eficaz
}

\author{
Ana Lúcia Neves de Moura ${ }^{1}$ \\ Marcos Gilson Gomes Feitosa ${ }^{2}$ \\ Bruno Campello de Souza ${ }^{3}$
}

\section{Resumo}

A consultoria interna surgiu a partir da necessidade das organizações de se manterem em processo permanente de renovação e vem se destacando nas últimas décadas pelo seu papel fundamental nos processos de mudança organizacional. A sua prática é baseada nos princípios da consultoria externa e se desenvolve sob um clima de conflitos, pressões e desgaste psicológico igual, se não superior, ao que se observa na consultoria externa. A partir da análise de três obras de Chris Argyris: Intervention theory and method: a behavioral science view (1970); Theory in Practice: increasing professional effectiveness (1974); e Maus conselhos, uma armadilha gerencial (2005), este ensaio teórico busca destacar contribuições valiosas que podem ajudar o consultor interno a superar os conflitos que caracterizam a sua atividade e a ter uma ação mais eficaz, criando um ambiente que favoreça o respeito, a confiança, a participação e a sinceridade, condições para gerar maior autonomia do cliente.

Palavras-chave: Consultoria interna. Competências.

\section{Introdução}

O campo da consultoria organizacional tem prosperado de forma crescente desde os anos 80 , pois, na época, motivados pela implementação de

\footnotetext{
${ }^{1}$ Mestre em Administração pela Universidade Federal de Pernambuco. Analista em Ciência e Tecnologia da Fundação Joaquim Nabuco. Endereço: Fundação Joaquim Nabuco, Coordenação-Geral de Recursos Humanos, Av. Dezessete de Agosto, 2187, Casa Forte, Recife, PE. CEP 52061 540. E-mail: ana.moura@fundaj.gov.br.

${ }^{2}$ Doutor em Educação pela Universidade Federal de São Carlos, SP. Professor adjunto do Programa de Pós-Graduação em Administração da Universidade Federal de Pernambuco. Av. dos Economistas, s/n, $1^{\circ}$ andar, sala D-4, Cidade Universitária, Recife, PE. CEP 50670901 E-mail: feitosam@terra.com.br.

${ }^{3}$ Doutor em Psicologia Cognitiva pela Universidade Federal de Pernambuco. Professor adjunto do Programa de Pós-Graduação em Administração da Universidade Federal de Pernambuco. Av. dos Economistas, s/n, $1^{\circ}$ andar, sala D-4, Cidade Universitária, Recife, PE. CEP 50670 901. E-mail: bcampello@uol.com.br. Artigo recebido em: 02/07/2008. Aceito em: 20/04/2009. Membro do Corpo Editorial Científico responsável pelo processo editorial: Thomas G. Brashear.
} 
ferramentas gerenciais inspiradas nas práticas de gestão japonesas, as consultorias se voltaram para a interpretação e implementação dessas práticas nas empresas (DONADONE, 2003). Foi na década de 90 que as empresas de consultoria, principalmente aquelas ligadas à consultoria organizacional, despontaram "como um dos setores mais dinâmicos do período", fomentadas pelas mudanças organizacionais associadas aos redesenhos organizacionais e pelo desenvolvimento da área da tecnologia da informação (DONADONE, 2005, p. 27).

A expansão da atuação das organizações além das suas fronteiras originais certamente também é um dos motivos propulsores do aumento da demanda por conselhos estratégicos, na medida em que contribuiu para a emergência de novos competidores e, consequentemente, para o aumento das situações de incertezas e da instabilidade do ambiente em que atuam (WOOD JR; PAULA, 2004). Wooldridge (1997) associa o crescimento e a consolidação do negócio de consultoria a dois fenômenos desse cenário: a complexidade e a incerteza. A primeira cria confusão, a segunda cria medo e ambas criam uma demanda crescente para o conselho externo. Destacam-se ainda, as novas formas de relacionamento com o cliente externo, tendo em vista o aumento do seu nível de exigência, e com o cliente interno, em função das novas relações entre empresa e empregados.

Paralelamente ao crescimento da consultoria organizacional e em função do mesmo cenário de globalização, novos conceitos gerenciais, empoderamento dos empregados e valorização dos clientes surgiram e vêm ganhando espaço nas organizações com a modalidade de consultoria interna.

O modelo de consultoria interna surgiu nos Estados Unidos e Europa em meados da década de 50, tendo ganhado força ao longo das décadas que se seguiram, de forma que nos início dos anos 80 a "consultoria interna era o segmento que mais crescia no negócio da consultoria". Na década de 90 essa modalidade destacou-se em função da "necessidade crescente de serviços de consultoria que ajudassem na mudança de cultura, estrutura $e$ práticas gerenciais das organizações" de forma que pudessem se tornar competitivas (JOHRI; COOPER; PROKOPENKO, 1998, p. 4). Já no Brasil, a consultoria interna teve início na década de 80 , também em resposta às demandas organizacionais decorrentes do cenário globalizado e instável (MANCIA, 1997; 2004). 
O surgimento e crescimento das consultorias internas são apontados não como um modismo, mas como uma resposta às exigências do cenário (MANCIA, 2004) a partir do "reconhecimento de que a renovação, mais do que a simples mudança organizacional, deve ser um processo permanente da organização" (GONÇALVES, 1991, p. 94). Mancia (1997, p. 16) acrescenta, ainda, que a consultoria interna surge como "uma alternativa viável para o desenvolvimento organizacional", que tem como objetivo "responder de maneira ágil e inteligente às necessidades organizacionais".

Johri, Cooper e Prokopenko (1998, p. 4), por sua vez, identificam na consultoria interna uma possibilidade da empresa resolver os problemas de seus departamentos sem ter que criar assessorias permanentes em cada unidade de trabalho ou contratar serviços externos (consultoria externa) para isso, e identificam no consultor interno um agente de mudança, responsável por "influenciar e aconselhar pessoas, e persuadi-las e ajudá-las a fazer as coisas de forma diferente". Esses autores acrescentam que a

[...] consultoria interna é o refinamento na evolução do conceito de staff, um conceito que enfatiza tornar disponível para o gerente uma fonte especializada dentro da organização para ajudá-lo na identificação e estudo de problemas e oportunidades, elaborando recomendações e assessorando na sua implementação.

A consultoria interna, então, surge e se desenvolve sob o modelo da consultoria externa e em resposta ao mesmo contexto que a impulsionou. Contudo, o fato de estar inserida no âmbito da organização faz com que apresente características próprias e coloca o consultor interno diante de situações e desafios específicos dessa modalidade, como será visto mais adiante.

Este ensaio apresenta mais quatro seções. A Seção 2 apresenta a metodologia; a Seção 3 descreve a dinâmica da consultoria interna, destacando suas principais características e benefícios, apresenta ainda um breve resumo dos estudos de Chris Argyris sobre consultoria, com os pontos de destaque; na quarta seção discutem-se as contribuições desses estudos para uma ação mais eficaz do consultor interno; e a última seção traz as conclusões e indicações para futuros estudos. 


\section{Metodologia}

Uma análise da literatura relacionada à consultoria interna (GEBELEIN, 1989; BLOCK, 1991; MANCIA, 1997; ELTZ; VEIT, 1999; KENTON; MOODY; TAYLOR, 2003) revela a necessidade de uma maior formação do consultor interno, de modo que ele não seja apenas um profissional com uma expertise, o que levaria a um entendimento reducionista do que consiste a ação do consultor, mas que tenha competências, habilidades e conhecimentos no campo da consultoria.

Considerando que parte dos estudos de Chris Argyris está voltada para temas ligados à consultoria, fruto de sua larga experiência nessa área, propõe-se neste ensaio teórico destacar aspectos desses estudos que podem contribuir para que o consultor interno supere os conflitos próprios de sua atividade e tenha uma ação mais eficaz junto aos clientes, a partir da análise de três obras desse autor - Intervention theory and method: a behavioral science view (1970), Theory in Practice: increasing professional effectiveness (1974), escrito em conjunto com Donald Schön, e Maus conselhos, uma armadilha gerencial: como distinguir os conselhos eficazes daqueles que não têm valor (2005).

Para este ensaio teórico, os critérios metodológicos basearam-se inteiramente na leitura e análise dessas três obras de Chris Argyris, a fim de permitir uma reflexão sobre a relevância desses estudos para o desenvolvimento da consultoria interna.

A escolha do autor deve-se ao fato de que apesar da crescente importância da atividade de consultoria para as organizações e o crescimento vertiginoso dessa atividade nas últimas décadas, não há ainda uma teoria ou modelos teóricos de consultoria. Os estudos realizados normalmente são escritos por consultores relatando experiências em intervenções ou textos instrucionais (manuais). Argyris, por sua vez, tem seu foco de estudo voltado para a compreensão do comportamento humano (ação humana) e de como isso pode inibir ou favorecer o autodesenvolvimento e o desenvolvimento dos outros, colocando essa compreensão como fundamental na atividade de consultoria, seja para uma ação mais eficaz tanto do consultor como do cliente, sem perder de vista a importância da autonomia (de ambos - consultor e cliente). Este ensaio, portanto, não aborda aspectos operacionais ou técnicos de consultoria interna, tendo seu enfoque na área de comportamento organizacional. 
A escolha dos livros se deu por eles terem sido objeto de estudo na disciplina "Organizações e Processos de Aprendizagem: a contribuição de Chris Argyris" do Mestrado em Administração da Universidade Federal de Pernambuco.

Após a leitura e síntese dos livros, foram selecionados os aspectos considerados centrais nesses estudos. Em seguida procurou-se fazer a correlação dos estudos de Argyris com o tema e suas possíveis contribuições para o desenvolvimento da consultoria interna.

\section{Fundamentação Teórica}

\subsection{Conhecendo a Dinâmica da Consultoria Interna}

O ambiente da consultoria organizacional tem sido retratado em vários estudos como sendo "um palco de relações, conflitos, contradições, dilemas e escolhas" (WOOD JR; PAULA, 2004, p. 10), cuja relação consultor/cliente "está marcada por uma série de mal-entendidos", levando a incompreensões de ambas as partes do que cada um espera do outro (MOURA, 2005, p. 12) $e$ apresenta "condições de trabalho marcadas por conflitos, paradoxos $e$ ambiguidades", submetendo os consultores a "situações de pressão" e "desgaste psicológico", levando-os a experimentarem "sentimentos de injustiça, impotência e frustração" (WOOD JR; CALDAS, 2005, p. 89).

A consultoria interna, por sua vez, não está livre desse ambiente de conflitos. Por constituir "sua prática baseada nos princípios e modelos de consultoria externa", ao mesmo tempo em que se apresenta como uma nova forma de trabalho por estar "inserida no ambiente organizacional" (MANCIA, 2004, p. 147), a consultoria interna apresenta características próprias que corroboram para um ambiente de conflitos, pressões e desgaste psicológico igual, se não superior, ao que se observa na consultoria externa.

Block (1991) destaca que o fato do consultor interno fazer parte do quadro de pessoal da empresa o coloca em uma situação bem específica e conflituosa: o número de clientes potencial é limitado ao universo de gerentes da empresa; o status do consultor interno e o nível do seu cargo são conhecidos pela maioria dos funcionários, o que limita seu acesso às pessoaschave; o consultor interno faz parte da hierarquia e das políticas da empresa; e o consultor interno responde a um chefe, que tem expectativas em relação 
ao seu trabalho, e se relaciona com clientes que também têm expectativas, sendo necessário um esclarecimento entre as partes envolvidas sobre os resultados esperados.

Lacey (1995) acrescenta, ainda, que outros aspectos próprios da consultoria interna que podem contribuir para esse ambiente de conflito:

a) Confusão de papéis - os gestores e demais interessados nessa relação geralmente pressionam o consultor interno para que ele assuma trabalhos que vão além do seu papel. É importante que o consultor deixe claro qual o seu papel na intervenção e quais as responsabilidades do cliente.

b) Compartimentalização - o consultor interno se vê ainda, dentro de um processo estressante de monitorar e conciliar tanto os acordos de confidencialidade das informações, como as promessas de interceder em favor de outros. Ele deve lembrar e agir em conformidade com esses acordos e promessas, de forma que ao usar as informações colhidas o faça de maneira consciente.

c) Marginalidade - o fato do consultor interno se mover livremente entre a organização, assumindo intervenções em dois ou mais departamentos, o coloca diante de grupos que possuem necessidades e objetivos diferentes, podendo contribuir para que ele se sinta isolado e solitário na tarefa de estudar soluções que integrem as especificidades de cada grupo. Eltz e Veit (1999) chamam a atenção para o fato de que lidar simultaneamente com clientes diferentes, com demandas e características diversificadas, também pode gerar conflitos de envolvimento e dedicação.

d) Ciúmes - o fato de o consultor interno ocupar uma posição de influência torna-o susceptível à inveja por parte de outros atores organizacionais, principalmente quando o consultor assume cargos gerenciais (é comum que pelo destaque do seu trabalho receba convites para assumir cargos de chefia). Outros membros da organização também podem se questionar sobre o porquê do consultor interno ter acesso a pessoas-chave da organização e participar de processos de tomadas de decisões. 
e) Carreira difusa - a ausência de uma carreira estruturada pode dificultar a legitimação do consultor interno, contribuindo para que ele seja visto pelo cliente como mais um membro do grupo. Mancia (1997; 2004) e Orlickas (1999) constatam que embora a atividade de consultoria interna venha ganhando espaço nas últimas décadas, a maioria das empresas não tem adotado a denominação de consultor interno como um cargo formalmente constituído. Desenvolve-se a função de consultor interno, mas o cargo não faz parte do plano formal de cargos das empresas. Quem desenvolve essa atividade é geralmente um funcionário que se destaca pelo seu conhecimento e experiência.

Com o propósito de salientar as características próprias da consultoria interna, Lacey (1995) faz uma comparação com a consultoria externa, a partir das fases que compõem uma intervenção - entrada, contratação, diagnóstico, intervenção e avaliação. A essas fases acrescentou-se a saída, que caracteriza a conclusão do trabalho do consultor.

Na consultoria interna a fase de entrada é de certa forma mais tranquila e exige menos tempo para o consultor interno do que o observado na consultoria externa, visto que o mesmo, por ser da organização, conhece as pessoas, a linguagem utilizada e os processos. Contudo, um aspecto a ser destacado é que o projeto apresentado pelo gerente do consultor interno pode não ser de seu interesse e, nesse caso, ao contrário do consultor externo, ele não pode recusar o trabalho. Lacey (1995, p. 77) esclarece que do consultor interno "é esperado que trabalhe - e trabalhe bem - com qualquer e todo funcionário na organização, independente de preferências ou estilo pessoais".

Na fase de contratação as diferenças se mantêm. Enquanto que na consultoria externa é elaborado um contrato formal, em que ficam resguardados tanto os direitos e os deveres do consultor como os do cliente, na consultoria interna muito do que é acordado fica apenas no campo verbal.

Lacey (1995, p. 77) chama a atenção para essa informalidade, tão maior quanto é a familiaridade entre consultor e cliente, esclarecendo que é primordial que seja elaborado um contrato com o cliente que considere pelo menos quatro questões: "a confidencialidade, a entrega de más notícias, o papel do consultor e a extensão do envolvimento pessoal do cliente com o processo de mudança". Essas questões uma vez acordadas com o cliente con- 
tribuirão para "fortalecer a relação consultor-cliente; preparam o cliente psicologicamente para a possibilidade de ouvir mensagens duras e permitem que os consultores (internos) dirijam-se a questões normalmente evitadas pelos outros (funcionários)".

Os limites na relação consultor-cliente também devem ser observados, de forma que o consultor não assuma responsabilidades não inerentes à sua função e o cliente tenha clara a sua responsabilidade pela execução do processo e pela garantia dos resultados (HIEBERT; OLTHUIS, 1995; ELTZ; VEIT, 1999; KENTON; MOODY; TAYLOR, 2003).

Ainda em relação à contratação, Block (1991) esclarece que a consultoria gera um tipo de contrato triangular (chefe do consultor-consultor-cliente) ou retangular (chefe do consultor-consultor-chefe do cliente-cliente). A primeira requer um entendimento prévio entre o chefe do consultor e o consultor, no que se refere às expectativas do trabalho a ser realizado. Na segunda, o chefe do consultor e o chefe do cliente devem ter o mesmo entendimento do trabalho a ser realizado, e eles por sua vez o repassam a seus subordinados. Assim, em ambos os casos é imprescindível que o consultor interno tenha claro quais são as expectativas de cada uma das partes.

A fase de diagnóstico, por sua vez, é normalmente a fase na qual o consultor externo entra em contato pela primeira vez com muitos membros da organização. E, embora ele chegue com o prestígio e status de um consultor pago, o estabelecimento de confiança e rapport são imprescindíveis para o sucesso do trabalho, de forma a garantir informações confiáveis. Lacey (1995) esclarece que no caso do consultor interno o seu status reside na posição que ocupa e nas relações (com pessoas-chave) que desenvolve dentro da organização. Isso vai interferir na disponibilidade dos respondentes em dizer a verdade durante a fase de coleta de dados.

Outro aspecto a ser considerado é o grau de abertura acordado no contrato. Quanto maior a credibilidade do consultor interno maior a possibilidade de conduzir o processo de mudança de forma mais aberta, sem a necessidade de recorrer ao anonimato e à confidencialidade.

A intervenção normalmente só é iniciada pelo consultor externo se ele identifica no cliente a possibilidade de informação válida, escolha livre e informada e comprometimento interno, ou seja, se o sistema está aberto à aprendizagem (ARGYRIS, 1970). No caso da consultoria interna Lacey (1995, p. 80) alerta para o fato de que a escolha livre e informada "é um luxo nem sempre concedido aos membros da organização". Escolha livre e informada 
pressupõe o direito das pessoas participarem ou não do processo de mudança, mas essa possibilidade nem sempre é colocada para os funcionários. Assim, no intuito de conseguir o comprometimento interno dessas pessoas, o consultor interno procura envolvê-las desde o início no processo de mudança, mesmo que para isso seja necessário o emprego de meios de colaboração, cooptação ou obrigação.

Outra característica da consultoria interna destacada por Lacey (1995) é a continuidade. O consultor interno acompanha o seu trabalho desde o desenvolvimento da ideia do projeto até a sua conclusão. Hiebert e Olthuis (1995) afirmam que o modelo de consultoria interna oferece consultoria de ciclo completo: estabelece as questões a serem trabalhadas, fazem as recomendações e lideram a mudança.

A fase de avaliação ocorre durante toda a ação, de forma que correções sejam possíveis, e ao final do processo, para monitorar em que medida a mudança foi realizada.

O consultor interno tem a vantagem de assistir o projeto de mudança tornar-se institucionalizado e assumir o papel no monitoramento das atividades que apoiam e asseguram o sucesso do projeto de mudança (LACEY, 1995, p. 81).

Na última fase da intervenção - a saída - a consultoria interna também apresenta diferenças significativas da consultoria externa. Kenton, Moody e Taylor (2003) inferem que a fase de saída é um desafio para o consultor interno. Enquanto que na consultoria externa o tempo é determinado e custa caro, na consultoria interna o tempo é livre, e o consultor acessível e disponível. Como normalmente constrói laços mais fortes, os consultores internos podem ter dificuldade de dizer "não" aos seus clientes (mesmo quando não se trata de questões estratégicas ou prioritárias, mas apenas de problemas operacionais) correndo o risco de se envolverem no trabalho de tal forma que se tornem mais um membro do grupo, dificultando sua disponibilidade para assumir outros projetos e a clareza quanto ao papel da consultoria interna (além de não contribuir para a autonomia do cliente, criando dependência e o risco dos clientes se sentirem vulneráveis com a saída do consultor).

Nesse caso, o consultor interno pode ter dificuldade de ser percebido pelo cliente como um expert que pode ajudá-lo - tornando-se mais um mem- 
bro da organização - de modo que os projetos estratégicos e mais desafiadores são destinados aos consultores externos. Contudo, afirmam Huffington $e$ Brunning (1994) se a consultoria for bem-sucedida, a equipe desenvolve a competência que lhes permitirá prosseguir com o trabalho sem a presença do consultor, o que não o impede de monitorar e avaliar as ações.

Apesar do ambiente de conflito e ambiguidade, os benefícios da consultoria interna são inegáveis. Kenton, Moody e Taylor (2003) afirmam que com a consultoria interna a organização tem a chance de maximizar o conhecimento e a competência existentes no sistema alcançando melhores resultados, enquanto os consultores internos ampliam o seu desenvolvimento profissional.

Kelley (1979) enumera quatro razões pelas quais as empresas deveriam adotar o modelo de consultoria interna, sendo as seguintes: resposta rápida, responsabilidade pessoal, baixo custo e campo de capacitação:

a) Resposta rápida: uma consultoria externa normalmente requer tempo para conhecer a organização e avaliar o problema. A consultoria interna, por sua vez, tem condições de dar atenção imediata, por estar na organização e pular determinadas etapas e por estar familiarizado com as políticas e com o estilo de gestão.

b) Responsabilidade pessoal: ao contrário do que ocorre na maioria das intervenções realizadas por consultores externos, os consultores internos envolvem-se no monitoramento e ajustes da implementação de suas sugestões. O seu trabalho só está concluído e o seu desempenho avaliado com a conclusão da implementação, de forma que as condições para que a implementação ocorra com sucesso são realmente consideradas, antes que o consultor interno faça suas recomendações.

c) baixo custo: a consultoria interna apresenta um custo significativamente menor do que a consultoria externa. Contudo, Kelley (1979, p. 113) chama a atenção para o fato de que essa economia em relação à consultoria externa só ocorre

[...] se eles (os consultores internos) se mantêm ocupados e se eles economizam mais dinheiro (através de suas soluções para os problemas da organização) do que fariam os seus pares externos. 
d) Campo de capacitação: a atividade de consultoria interna propicia ao funcionário uma visão global da organização, além de oportunidades de lidar com situações de resolução de problemas, o que funciona como uma preparação para posições de alta gerência.

Mancia (2004) destaca, ainda, que a atividade de consultoria interna contribui para a ampliação e redimensionamento das competências do profissional, em função dos novos conhecimentos, habilidades e atitudes exigidas.

Ao mesmo tempo em que traz benefícios para a organização, o fato de a consultoria interna estar inserida no ambiente organizacional cria ambiguidades e conflitos que podem impactar na atuação do consultor interno. Nesse sentido, os estudos de Chris Argyris sobre consultoria e a sua preocupação em examinar o papel dos consultores e as relações que eles criam com seus clientes de modo a ajudá-los a serem mais competentes e eficazes podem contribuir para que esses desafios sejam vencidos.

\subsection{O Que Argyris Tem a Dizer Sobre Uma Intervenção Eficaz}

\subsection{Ação Proclamada X Ação Praticada}

Argyris e Schön (1974) defendem a integração entre pensamento e ação na busca de uma maior eficácia na ação, ao mesmo tempo em que colocam essa questão como um dos problemas mais relevantes e menos compreendidos de nosso tempo. Os autores chamam a atenção para o fato de que a competência para implementar a ação, refletir sobre ela enquanto ocorre, de forma a daí tirar alguma aprendizagem, é importante e pode ser praticada por todas as pessoas.

Ao estudar o comportamento humano (ação humana) pode-se tanto considerá-lo como uma relação entre fenômenos publicamente observáveis, assim como uma consequência das teorias de ação praticadas pelos homens. Nesse caso, o comportamento humano poderia ser explicado ou previsto com base em uma teoria de ação. A teoria de ação seria composta por um conjunto de pressupostos com o objetivo de abranger todas as condições sob as quais se poderia chegar à ação eficaz. A teoria de prática, por sua vez, comporta um conjunto de teorias de ação interrelacionadas que, sob pressupostos relevantes, produzirão consequências intencionadas. "As teorias de prática normalmente contêm teorias de intervenção - isto é, teoria de ação com objetivos de eficácia" (ARGYRIS; SCHÖN, 1974, p. 6). 
Argyris e Schön defendem que para o entendimento das teorias de prática se faz necessária uma maior compreensão sobre as teorias de ação. Esses autores distinguem dois tipos de teoria de ação: a teoria proclamada e a teoria praticada. A teoria proclamada é aquela que o indivíduo anuncia aos outros, quando solicitado. A teoria praticada ou em uso, por sua vez, é aquela que efetivamente governa o seu comportamento.

Para se identificar a teoria praticada, não basta perguntar ao indivíduo como ele se comporta (uma vez que o que ele professa pode não corresponder à sua prática), se faz necessário observar o comportamento da pessoa. Essa incompatibilidade entre o professado e o praticado pode ou não ser consciente, assim como pode ser decorrente tanto de variáveis internas da pessoa, como de variáveis situacionais.

Argyris e Schön (1974) afirmam que cada indivíduo tem não apenas uma teoria praticada, mas várias teorias para cada tipo de situação que se depara regularmente. Seriam microteorias alinhadas a uma teoria maior que de certa forma regeria ou guiaria essas microteorias, conforme a situação vivenciada. As teorias praticadas podem criar um mundo comportamental limitador ou libertador, dependendo de questões relacionadas às suas consistências internas, congruências, testabilidade e eficácia, além do valor que damos ao mundo comportamental que criamos.

A consistência interna refere-se à ausência de contradições, sendo que neste caso, um dos aspectos imprescindíveis seria a ausência de contradições entre as variáveis que orientam a ação (variáveis governantes).

A congruência é a existência de coerência entre a teoria proclamada e a teoria praticada. Isso se traduz não só em um comportamento correspondente à teoria proclamada, mas também à "expressão de sentimentos internos em ações" (ARGYRIS; SCHÖN, 1974, p. 23). A Congruência mostra uma integração entre o estado interno do sujeito com o externo ao sujeito, assim tanto quem o conhece como quem observa o seu comportamento percebe essa integração entre o que ele diz (ou crê) e o que faz.

As teorias de ação são testáveis "na medida em que alguém puder especificar a situação, o resultado desejado e a ação mediante a qual o resultado deve ser alcançado". Se a ação levar aos resultados esperados, a teoria terá sido confirmada, caso contrário terá sido desconfirmada (ARGYRIS; SCHÖN, 1974, p. 25).

A eficácia da teoria praticada, por sua vez, é avaliada considerando em que medida a ação, congruente com a teoria, alcança as variáveis governantes. 
Argyris e Schön (1974) alertam para o fato de que, em função da valorização que damos à constância da teoria praticada e do nosso mundo comportamental, tendemos a preservá-los e protegê-los dos dilemas utilizando certos mecanismos de defesa de forma que os outros não percebam as incongruências.

O modelo de teorias praticadas (aqui descrito de forma muito simplificado) deve ser construído a partir da descrição de casos vivenciados pelo sujeito, em que se deve constar o que ele efetivamente disse, quais eram suas reais intenções com o que falou, como os participantes efetivamente se comportaram e como responderam. Feito isso, as informações são analisadas e reflete-se sobre o que foi professado, as intenções, e o efetivamente praticado.

Os principais objetivos da construção de teorias praticadas são: ajudar as pessoas a se tornarem mais eficazes nas suas interações com os outros, permitir o autodesenvolvimento, permitir o conhecimento de suas práticas, de como elas inibem ou favorecem o desenvolvimento dos outros, e de como melhorá-las (ARGYRIS; SCHÖN, 1974).

\subsubsection{Modelo II: um modelo a ser perseguido}

Argyris e Schön (1974, p. 35) identificam dois modelos de teoria de ação: Modelo I e Modelo II e discriminam as variáveis governantes que orientam as teorias de ação de cada modelo, descrevem as estratégias de ação correspondentes a essas variáveis e as consequências para o mundo comportamental e para a aprendizagem, o que corresponderá a uma ação de eficácia crescente ou decrescente.

Como características do Modelo I Argyris e Schön (1974) destacam: controle unilateral do ambiente e das tarefas, comportamento político, comportamento racional e o intuito de vencer a qualquer custo. Essas variáveis governantes levam a estratégias de ação de domínio e controle que, por sua vez, implicam em comportamento defensivo, controlador e manipulador $e$ em relações construídas com base na desconfiança e rivalidade. Esse modelo de teoria de ação culmina em aprendizagem de ciclo único e eficácia decrescente.

A longo prazo, o Modelo I vai "aumentar a defensividade entre as pessoas e a tornar disfuncionais os comportamentos inter e intragrupais". Esse mundo apresenta características ambíguas na medida em que é competitivo e civilizado, ao mesmo tempo em que utiliza mecanismos de repressão e con- 
tenção das emoções, gerando um ambiente tenso, defensivo e autorreforçador, tendendo a uma estagnação (ARGYRIS; SCHÖN, 1974, p. 80).

Embora o Modelo I apresente um tipo de aprendizagem disfuncional, Argyris e Schön (1974) inferem que não é de se estranhar que as pessoas persistam nesse modelo, uma vez que a sociedade de certa forma funciona sob essa perspectiva. Os adultos são ensinados a valorizar a atribuição e a avaliação social, ou seja, a atribuição de valores aos outros, assim como a comparação com os outros, sem um teste aberto.

O fato das pessoas, na grande maioria, não terem consciência de suas teorias praticadas, leva Argyris e Schön (1974) a concluírem que, muito provavelmente, a tendência das pessoas se dirigirem ao Modelo I é inconsciente. As pessoas reforçam e valorizam aspectos desse modelo, atribuindo-lhe a qualidade de expressar maturidade, compostura e dignidade, sem a devida consciência de como se comportam com tais valores. Uma vez que esses comportamentos e valores são reforçados nos grupos e nas instituições, cada vez menos as pessoas percebem a necessidade de mudá-los.

O Modelo II, por sua vez, tem como características: maximização das informações válidas, da escolha informada e livre e do comprometimento interno. Essas variáveis governantes levam o indivíduo a desenvolver estratégias de ação em que o controle é compartilhado, implicando em comportamento colaborativo e em relações construídas com base na confiança, na abertura e cooperação. Esse modelo culmina em aprendizagem de ciclo duplo e maior (e crescente) eficácia na resolução de problemas e nas tomadas de decisão. Argyris e Schön (1974) acreditam que as ações do Modelo II são capazes de reduzir as disfunções do Modelo I, promovendo o crescimento, a aprendizagem e a eficácia.

A propriedade mais significativa desse modelo, segundo Argyris e Schön (1974), seria a sua propensão a não ser auto-oclusivo, o fato de oferecer, progressivamente, testes mais eficazes dos pressupostos e de propiciar mais aprendizagem sobre a eficácia da pessoa. Esses autores acreditam em uma grande demanda para tal modelo, considerando que ele contém variáveis valorizadas pelas pessoas, que são normalmente proclamadas amplamente, mas pouco praticadas.

As pessoas que se comportam de acordo com o Modelo II são vistas como menos defensivas, abertas à aprendizagem, facilitadoras e colaboradoras. Pessoas comprometidas com suas teorias praticadas e, consequentemente, comprometidas com a confrontação e teste dessas teorias. Essas pessoas ten- 
derão a buscar feedback com o propósito de atingir maior eficácia nas suas ações. O feedback virá em forma de informação válida, retroalimentando o modelo (ARGYRIS; SCHÖN, 1974).

O comportamento do Modelo II interfere na dinâmica do grupo, visto que o clima de confiança, participação, liberdade, entre outros, facilita a aprendizagem e o crescimento de todos. "O Modelo II ensina as pessoas a envolverem outras pessoas relevantes na definição de que variáveis devem ser importantes e de quais devem ser as relações das variáveis". Esse modelo conduz tanto à aprendizagem de ciclo único quanto à aprendizagem de ciclo duplo (ARGYRIS; SCHÖN, 1974, p. 93).

Argyris e Schön (1974) explicam que o Modelo II deve ser visto nesse processo como o modelo a que aspiramos e que, portanto, guiará a definição dos objetivos aptos a satisfazer as variáveis governantes de: informação válida, escolha livre e informada e comprometimento interno com a escolha.

O processo de transição do Modelo I para o Modelo II pode ser resumido nos seguintes passos: 1) identificação de inconsistências, que devem ser validadas, e dos papéis do agente na produção de um comportamento ineficaz; 2) se há interesse em reduzir a consequência da ineficácia, é iniciada a exploração de alteração das variáveis governantes, o desenvolvimento de novas estratégias de ação e a exploração das consequências para o mundo comportamental, para a aprendizagem e para a eficácia; 3) testar a aprendizagem a partir de testes não comportamentais (discussão cognitiva) das teorias proclamadas do agente e dos outros; 4) teste público do novo comportamento, para confirmação ou desconfirmação; e 5) internalização dos novos comportamentos (e responsabilização por eles), a partir da percepção de que esses comportamentos aumentam a eficácia (ARGYRIS; SCHÖN, 1974).

Para que isso aconteça, Argyris e Schön (1974) orientam que os profissionais deverão desenvolver microteorias de ação que, organizadas, representarão uma teoria eficaz de prática. É imprescindível que o profissional tenha a capacidade de agir segundo as suas microteorias de ação, de refletir sobre as suas ações relacionando-as com as variáveis governantes implícitas no seu comportamento e determinando o impacto do seu comportamento sobre o próprio mundo comportamental, sobre a aprendizagem e sobre a sua eficácia.

Argyris e Schön (1974, p. 93) esclarecem que nos seus estudos não buscaram encorajar o comportamento do Modelo I ou do Modelo II, mas encorajar o comportamento mais eficaz. Buscou-se "identificar o padrão de 
variáveis de que o agente precisa para manejar, se ele quer ser eficaz em qualquer situação", e o Modelo II atinge esse objetivo.

\subsubsection{Os Três Elementos Primários e a Autonomia do Sistema-Cliente}

A intervenção pressupõe a existência de um sistema que existe independentemente do agente que intervém. O ato de intervir, por sua vez, implica no relacionamento do agente com pessoas, grupos ou objetos, com o objetivo de ajudá-los. Essa relação pode favorecer a autonomia do sistemacliente ou causar uma dependência. Argyris (1970, p. 16) propõe que o interveniente deve centrar sua ação no propósito de "manter ou aumentar a autonomia do sistema-cliente", que deve haver uma diferenciação clara dos limites entre o sistema-cliente e o interveniente e uma conceituação da saúde do sistema-cliente independentemente da do interveniente.

Argyris (1970) defende que o sistema cliente deve procurar ser autônomo, autorresponsável e controlar o seu próprio destino. O papel do interveniente nessa relação é ajudar o sistema a se tornar mais eficaz na solução de problemas e na tomada e implementação de decisões. Esclarece também que a preocupação do interveniente deve ser ajudar não apenas a diretoria, mas o sistema como um todo, de forma que todos tenham a oportunidade de aumentar a sua competência e eficácia. Conclui, ainda, que para a atividade de intervenção realmente auxiliar os membros do sistema, ela deve ocorrer sob as seguintes condições: geração de informação válida, escolha livre e informada (de modo que o sistema-cliente mantenha seu discernimento e autonomia), e comprometimento interno do cliente em relação às suas escolhas, à aprendizagem e à mudança (não por acaso as variáveis governantes que orientam o Modelo II).

A informação válida e útil é apresentada por Argyris (1970, p. 17) como a base para uma intervenção eficaz. A informação válida pressupõe a verificação pública, quando "vários diagnósticos independentes sugerem um mesmo quadro"; a predição válida, baseada nos diagnósticos independentes e confirmada posteriormente; e o controle sobre os fenômenos, de forma que possa "predizer os efeitos sobre o sistema como um todo". É importante que, além de válida, a informação seja útil, que possibilite ao cliente usá-la para alterar os seus sistemas e promover uma mudança eficaz.

A escolha livre, por sua vez, deve ser voluntária e proativa, ao invés de automática e reativa. $\mathrm{O}$ interveniente deve resistir nos casos em que o 
cliente procura transferir para ele a tomada de decisão. Essa condição é importante para que o cliente se sinta motivado e comprometido em trabalhar o problema diagnosticado (ARGYRIS, 1970).

Já o comprometimento interno exige que a escolha tenha sido internalizada pelos membros do sistema-cliente, de forma que eles experimentem "um alto grau de pertença e tenham um sentimento de responsabilidade sobre a escolha e suas implicações". O cliente sabe que está influindo na escolha e passa a agir sob a influência de forças internas e não de forças induzidas. Essa situação favorece um clima de baixa dependência, de comprometimento forte por um longo período e de abertura para reexame de sua ação (baseada em informações válidas) (ARGYRIS, 1970, p. 20).

Argyris e Schön (1974) esclarecem que essas três variáveis funcionam de forma interligada, de modo que a informação válida é essencial para a escolha informada, a liberdade de escolha é também influenciada pela informação válida, pois só assim a pessoa poderá definir objetivos coerentes com as suas capacidades, e influencia tanto no comprometimento como no monitoramento, considerando que se você tem liberdade de escolha se sente mais responsável pelas suas decisões.

Para que a intervenção ocorra com sucesso é imprescindível que os clientes estejam envolvidos em todas as etapas da mudança, contribuindo para a elevação do comprometimento interno (e para que se sintam responsáveis por sua implementação), e que o interveniente focalize as relações interpessoais e as dinâmicas de grupo, de forma que, feito isso, o sistemacliente seja capaz de conceber, executar e monitorar as suas mudanças na estrutura, no sistema de poder, entre outros.

Uma maior influência dos clientes nas fases da intervenção vai gerar uma relação mais orgânica com o sistema-cliente. Argyris (1970) esclarece que essa relação será tão mais orgânica quanto mais inclua as seguintes dimensões: participação dos indivíduos na definição dos objetivos; encorajamento para que esses confrontem e testem suas relações com o interveniente; volume de participação influenciado pelo indivíduo e pelo interveniente; encorajamento dos clientes para que participem e controlem o programa, de forma que esses se sintam tão envolvidos e responsáveis quanto o interveniente; participação dos clientes na concepção do instrumento, métodos e estratégia de mudança; participação dos clientes na definição dos custos e recompensas do programa de mudança; feedback aos sujeitos com o objetivo de mobilizá-los e ajudá-los a desenvolver a relação. 
A intenção é envolver os clientes em todas as fases do programa, aumentar as oportunidades de sucesso psicológico, elevar os sentimentos de essencialidade, a confiança nos outros e a possibilidade de formar um grupo eficaz. Essas atitudes, por sua vez, contribuirão para que sejam alcançadas as atividades primárias: informação válida, escolhas informadas e comprometimento interno (ARGYRIS, 1970).

\subsubsection{Fugindo da Armadilha dos Maus Conselhos}

Dentre os principais papéis desempenhados pelo consultor - interno e externo - também está o papel de conselheiro (KELLEY, 1979; GEBELEIN, 1989; LACEY, 1995). Em função da credibilidade, respeito e confiança construídos junto aos gestores, os consultores internos são frequentemente consultados pelos gestores em busca de conselhos. Os consultores internos se voltam para a necessidade de ajudar os clientes a serem mais bem-sucedidos nas suas ações gerenciais.

Argyris (2005) alerta para o fato de que muito dos conselhos que vêm sendo disseminados nas organizações - seja por gurus, acadêmicos, autores de livros ou consultores - implicam em ações ineficazes, na medida em que apresentam inconsistências internas, são abstratos e contribuem para ações defensivas e comportamentos dissimulados.

Outro aspecto constatado por Argyris (2005) é que muitas vezes os consultores, diante de situações embaraçosas e ameaçadoras se comportam de forma diferente dos conselhos que pregam, $e$ isso acarreta no distanciamento dos gerentes em relação aos programas de mudança propostos. Assim, ao desempenhar seu papel de conselheiro, o consultor deve estar atento à forma como desenvolve e implementa seus conselhos, de modo que eles não criem nem reforcem consequências indesejadas. Para que isso ocorra, Argyris (2005) destaca que é importante:

a) Evitar inconsistências e ambiguidade na elaboração dos conselhos, pois o que deve ficar claro são quais os resultados a serem atingidos e especificar o comportamento necessário para que isso ocorra e o detalhamento das ações que devem ser desenvolvidas. Isso permitirá não só que os mesmos sejam testados na vida real, mas também que sejam questionados. 
b) Haver congruência entre a teoria que o consultor professa e a que efetivamente pratica.

c) Empenhar-se em criar uma ambiência que favoreça a diminuição das defesas interpessoais, intergrupais e organizacionais, tornando as questões (ocultas ou reprimidas) mais explícitas e testando as suposições, avaliações e atribuições relacionadas a elas, de forma que os indivíduos se engajem em uma discussão justa e aberta (com base em informações concretas e verdadeiras que ilustrem o que está sendo afirmado), que leve a resultados mais produtivos. Esse ambiente de abertura e sinceridade - construído a partir do diálogo produtivo, que permita a possibilidade de confronto entre as opiniões e emoções do eu e outro - vai contribuir para que as verdadeiras causas dos problemas venham à tona e sejam tratadas.

Argyris (2005, p. 78) ainda chama a atenção para o fato de que quando as mudanças propostas exigem "novas teorias em uso, novas virtudes sociais e novas formas de diálogo organizacional", ou seja, quando implica em mudanças de ciclo duplo, o foco não deveria ser mudança de comportamento - como normalmente ocorre - mas a introdução de novas teorias em uso (teorias de ação do Modelo II).

Para que os indivíduos produzam novos comportamentos, infere o referido autor, é necessário que eles internalizem uma nova teoria em uso, o que será possível a partir de oportunidades de aprendizado que levem os indivíduos a desenvolverem habilidades do Modelo II e ao raciocínio produtivo.

Argyris (2005, p. 52) esclarece que muitas vezes os clientes consideram os conselhos úteis - mesmo que ineficazes - porque permitem que as pessoas permaneçam na sua zona de conforto mantida por comportamentos típicos do Modelo I. Os resultados ineficazes são atribuídos não aos conselhos, mas a "realidades intratáveis". Contudo, infere o autor, se sabemos que as ações são projetadas e se os erros são ações, os erros podem ser evitados, ou não repetidos, a partir de mudanças no projeto.

\section{Análise do Tema}

A partir das exposições contidas na seção anterior, destacam-se como aspectos centrais nos estudos de Argyris sobre a ação eficaz de intervenção: 
a preocupação em ajudar as pessoas a serem mais competentes; a preocupação em se criar um ambiente verdadeiramente democrático, que permita, como diz Dewey (1976), maior liberdade e relações humanas mais decentes e amáveis, contribuindo para uma experiência de maior propriedade e, portanto, uma aprendizagem de maior qualidade; a preocupação em gerar a autonomia do cliente; e a preocupação com o aprendizado transformador, que leve as pessoas a questionarem o que está orientando seus comportamentos (focando as causas e não os sintomas) e a assumirem novas (e mais eficazes) teorias de ação.

Argyris e Schön (1974, p. 162) chamam a atenção, ainda, para a importância de o profissional assumir responsabilidade por aquilo que faz. Eles afirmam que "o comprometimento de ser responsável é uma condição para a competência" e para uma teoria de prática eficaz. Isso requer do indivíduo um forte compromisso com ele próprio, o que permitirá que tenha um desempenho coerente com os seus escrúpulos, independente da aprovação de outros. Essa é uma situação enfrentada constantemente - uma verdadeira endemia - pelos profissionais: o confronto entre os seus valores e as demandas dos clientes. Diante desses conflitos os profissionais devem estar, pelo menos, conscientes sobre as consequências dos compromissos que assumiram ou deixaram de assumir, das escolhas que fizeram ou deixaram de fazer.

Essas preocupações, por sua vez, também deveriam estar presentes no trabalho do consultor interno. Orlickas (1999) constata, em sua pesquisa realizada em empresas que têm adotado a consultoria interna de gestão de pessoas, que o consultor interno é um profissional que faz parte do quadro permanente da empresa, ocupa um cargo de nível técnico ou gerencial, possui um perfil generalista na sua área de atuação e atua como facilitador.

Mancia (2004, p. 149) define da seguinte forma o consultor interno:

[...] funcionário de uma organização, especialista num campo de conhecimento e, por seu conhecimento nessa especialidade, por sua habilidade, experiência postura $e$ posição, exerce influência sobre diferentes segmentos da organização (pessoas e grupos), mas não possui poder decisório sobre seus clientes nem sobre os projetos e sua implementação.

A priori, portanto, não é exigido do consultor interno um conhecimento sobre a atividade de intervenção e suas implicações para ele próprio e 
para o cliente. Contudo, diante dos dilemas, das pressões e da complexidade com que tem que lidar no seu dia a dia, é imprescindível - além da expertise em determinada área - que o consultor interno estruture e organize a relação consultor-cliente, de forma a tornar as situações mais manejáveis, visando aumentar a probabilidade de sua eficácia e de construção de uma relação que favoreça a aprendizagem e o desenvolvimento do seu cliente e, consequentemente, potencialize a qualidade dos resultados obtidos.

É, portanto, sob a perspectiva de preparar melhor o profissional que vai atuar como interveniente, que o estudo da obra de Argyris pode trazer contribuições valiosas para que o consultor interno supere os conflitos que caracterizam essa atividade e tenha uma ação mais eficaz, destacando-se como aspectos fundamentais ao consultor interno:

1) Autoconhecimento - o consultor deve ter sua própria filosofia de intervenção e confiar nela, afirma Argyris (1970). Para que isso ocorra é necessário que o interveniente tenha um mapa cognitivo da teoria de intervenção, isso vai ajudá-lo a lidar com o processo de mudança, a avaliar o tipo de terreno pelo qual pode passar, além de contribuir para que ele mantenha sua autenticidade e ética. Um maior conhecimento da sua capacidade, dos seus limites, dos seus hiatos e inconsistências são resultados importantes quando se tem uma filosofia bem concebida.

Outra dimensão importante está relacionada às razões que levaram o indivíduo a se interessar pela atividade de intervenção. Argyris (1970, p. 143) esclarece que as motivações de um interveniente deveriam estar direcionadas para "ajudar a si próprio e os outros a estarem abertos, a aprender e aumentar em si e nos outros a consciência e a competência". Isso vai exigir dos intervenientes abertura, congruência e competência.

Assim, embora a intervenção deva ser um processo participativo, o consultor tem em suas mãos a condução do processo e conhecendo suas próprias limitações, competências e receios estará mais seguro na sua forma de agir.

2) Construir uma relação de qualidade com o cliente - a relações que o consultor interno mantém com o cliente devem ser autênticas e não parte de um jogo diplomático. Deve-se construir uma relação de confiança com cliente.

Essa confiança é importante para que o cliente se sinta à vontade tanto em pedir a ajuda do consultor interno como em aceitá-la, uma vez que saberá que essa relação será construída com base em valores e ética. Ter uma conduta diferente daquilo que professa, ou ainda apresentar um comporta- 
mento que varia de acordo com a audiência, são sinais de uma consultoria ineficaz (GEBELEIN, 1989).

O consultor interno deve, ainda, lidar com a familiaridade que tem com o cliente não como um aspecto dificultador nessa relação (facilitando a informalidade no que for acordado entre as partes), mas como um aspecto positivo, que pode contribuir para a criação de parcerias cooperativas com os clientes.

O consultor precisa também, ser capaz de compreender e encorajar o cliente a exprimir seus sentimentos de forma aberta: o interveniente deve aceitar os ataques e as desconfianças do cliente e ser capaz de ver esses comportamentos como uma tentativa do cliente de reduzir suas ansiedades e tensões. Esse momento de tensão pode ser revertido se o consultor interno usálo como oportunidade para desenvolver nos clientes experiências de aprendizagem e crescimento (ARGYRIS, 1970).

As diferenças na relação consultor-cliente que surgirem durante a intervenção devem ser trabalhadas, jamais dissimuladas, sob pena de invalidar a eficácia do trabalho do consultor. É importante que o interveniente esteja atento para os comportamentos diretamente observáveis; encoraje o feedback sobre ele; identifique o grau em que ocorre a comunicação diretamente verificável, minimamente atributiva e minimamente avaliativa, devendo o interveniente oferecer oportunidade de explorar e refletir sobre o impacto do feedback avaliativo e não diretamente verificável; e, diante das inconsistências identificadas, ajudar o cliente a ter consciência dessas inconsistências e do seu impacto sobre a sua competência interpessoal e sobre o seu relacionamento com os outros (ARGYRIS, 1970).

O consultor interno, portanto, deve ser hábil em gerenciamento de conflitos, de forma que seja capaz de criar um ambiente onde as discordâncias sejam expressas e os conflitos discutidos sempre de uma forma aberta e produtiva (GEBELEIN, 1989).

3) Considerar as questões interpessoais - Argyris (1970) afirma que é importante que as dimensões interpessoais sejam exploradas e trabalhadas pelo consultor até um nível satisfatório, sob o risco de criar conflitos, ambiguidades, tensão e preocupação nos funcionários. O consultor interno deve, portanto, buscar criar formas de ajudar os clientes a desenvolverem suas habilidades interpessoais e processos eficazes de grupo enquanto estão sendo resolvidos os problemas e, na medida em que a eficácia do grupo for 
aumentando, ele pode começar a trabalhar questões mais delicadas como confiança e confidência.

A ênfase nas questões interpessoais e comportamentais não significa que a racionalidade deva ser substituída pela emoção e a competência técnica pela competência interpessoal. O objetivo é que, com a abertura para que as pessoas possam exprimir o que sentem em relação ao relacionamento com os outros, os problemas técnicos possam ser mais eficientemente resolvidos (ARGYRIS, 1970).

4) Considerar as questões substantivas do cliente - é importante deixar o conflito aflorar, trazê-lo à discussão, de forma que questões essenciais à mudança sejam discutidas e confrontadas, pois só assim a mudança pode ser gerenciada de forma mais eficaz, levando a organização à competência e à eficácia. O diálogo, esclarece Argyris (1970), deve voltar-se para a identificação do problema, solicitando ao cliente que descreva como ele vê o problema: onde está o problema, nele, nos outros, no sistema, etc.; observar o uso do comportamento avaliativo, atributivo e descritivo; o grau de consistência da descrição; a facilidade e abertura com que o cliente fala das questões consideradas difíceis.

A observação do comportamento do cliente vai fornecer ao interveniente uma série de dados: como se manifestam o poder e a liderança, como os indivíduos identificam e cuidam da eficácia do seu grupo, o grau de dependência do grupo em relação tanto ao líder formal, quanto ao interveniente, o empenho do grupo na realização das tarefas, como o conflito é trabalhado no grupo, como os membros do grupo lidam com o interveniente, entre outros (ARGYRIS, 1970).

Argyris (1970) chama a atenção para a importância de distinguir no comportamento observado as variáveis genotípicas e fenotípicas. O consultor interno deve estar ciente de que as variáveis latentes (genotípicas) proporcionam uma compreensão dos problemas mais útil e completa do que a que se aplica às variáveis manifestadas (fenotípicas), ou seja, a situação do sistema deve ser explicada muito mais pelo que está por trás do comportamento do cliente (o que não é visível). Para o consultor interno - por elemento integrante da organização - esse processo pode ocorrer de forma mais tranquila, visto que está familiarizado com as pessoas e com as políticas adotadas na organização.

5) Manter e aumentar a autonomia do cliente - Argyris (1970) afirma que um sistema melhor é um sistema autônomo e independente, que 
seja capaz de controlar o seu comportamento e o seu destino, o que, em outras palavras, significa ser capaz de resolver os seus problemas e executar as suas decisões. A competência e a eficácia do sistema estão, portanto, relacionadas à capacidade de resolver problemas, tomar e implementar decisões.

Assim, quando o interveniente decide unilateralmente, sem envolver os gerentes da empresa, o projeto apresentado não é percebido como sendo do grupo, gerando, conseqüentemente, um nível baixo de comprometimento e ausência do sentimento de co-responsabilidade. Na medida em que apenas os intervenientes fazem de fato o trabalho, os clientes não desenvolvem as habilidades necessárias para que eles mesmos façam essas ações diagnóstico, prognóstico, tomada de decisões - de forma eficaz.

O fato do consultor interno não se envolver com os problemas organizacionais de forma temporária, com data de início e término, aumenta sua responsabilidade e o nível do seu envolvimento nas propostas por ele apresentadas (sem falar de sua presença constante na empresa) pode comprometer a autonomia do sistema se o consultor não estiver atento a essa questão.

Lacey (1995) nos lembra que por se deparar em alguns momentos com a impossibilidade de escolha livre e informada, que nem sempre é colocada para os funcionários, o consultor interno muitas vezes vai buscar o comprometimento interno dessas pessoas utilizando-se de meios de colaboração, cooptação ou obrigação. Em outras palavras, o consultor se vê utilizando meios de manipulação.

Sobre a manipulação Argyris (1970) destaca que os custos tendem a ser altos em comparação aos benefícios que podem gerar, pois o interveniente tende a gastar energia em: planejar a manipulação, de forma que ela não seja percebida pelos clientes; vender a manipulação como algo bom; controlar e neutralizar as resistências do cliente; e em lidar com o sentimento de perda de autoaceitação. Outro aspecto negativo é o de que a manipulação gera o comprometimento externo, não mais em função da natureza intrínseca do trabalho, mas em função de recompensas e de punições.

Uma forma de diminuir os custos da manipulação é o interveniente procurar fazer com que as pessoas compreendam a importância de alinharem suas relações à natureza das relações interpessoais eficazes. Não tendo sucesso, o interveniente deve assumir e admitir a necessidade da manipulação, perguntando ao grupo se são vistas alternativas. Permanecendo a manipula- 
ção, ela deve ser feita em atividades e relações rotineiras e por um curto período (ARGYRIS, 1970).

Nesse caso, o interveniente tem a responsabilidade de diminuir a necessidade de manipulação, assim como, a responsabilidade de, enquanto estiver manipulando, ajudar aos que estão sendo manipulados a explorar as razões e os impactos da manipulação. As pessoas devem ter abertura para expressar o seu descontentamento com essa situação e não poderá ser exigido que alguém goste da manipulação. Ou seja, as pessoas devem estar livres para questionarem a manipulação, tanto quanto a própria competência do interveniente (ARGYRIS, 1970).

6) Buscar as condições sine qua non à ação eficaz - Para que a atividade de consultoria seja competente e eficaz, ela não pode provocar mudanças que implique na redução da escolha livre ou do comprometimento interno, reduzindo a possibilidade do sistema-cliente se torna autorregulável. Argyris (1970, p. 21) infere que "um sistema-cliente será eficaz na medida em que for capaz de gerar a informação válida, a escolha livre $e$ informada e o comprometimento interno" (ou seja, agir de acordo com as teorias de ação do Modelo II).

Ao mesmo tempo, Argyris (1970, p. 172) chama a atenção para a complexidade do ciclo primário de intervenção - geração de informação válida, escolha livre e informada, e comprometimento interno (base para o Modelo II, e, portanto, para uma ação eficaz) - denominando-o "o calcanhar de Aquiles do interveniente e dos clientes", o que exigirá bastante da competência do consultor interno.

A combinação das ações descritas acima - autoconhecimento, relação de qualidade com o cliente, trabalhar as dimensões interpessoais, trabalhar as questões latentes do cliente e buscar a autonomia do cliente - vai gerar uma ambiência favorável à ação eficaz do consultor interno e, consequentemente, ao aumento da competência e eficiência do cliente. Buscar as condições sine qua non à ação eficaz, por sua vez, vai contribuir para a construção e o favorecimento de um ambiente de confiança, franqueza, autonomia e participação. 


\section{Conclusões Finais}

O desenvolvimento da atividade de consultoria interna no Brasil é relativamente recente e ainda pouco abordado na literatura acadêmica brasileira. É crescente, contudo, a importância dessa atividade nas organizações, pelo seu "papel fundamental nos atuais processos de mudança organizacional" (HANSEN, 1990 apud MANCIA, 2004, p. 147). Como mencionado no início deste ensaio, a consultoria interna surgiu a partir da necessidade das organizações de estarem preparadas para as exigências do cenário e se desenvolveu a partir do modelo da consultoria externa, porém inserida no âmbito da organização (GONÇALVES, 1991; MANCIA, 2004).

O consultor interno, por estar inserido na organização e, portanto, acompanhar os projetos desde a sua concepção até a sua conclusão; estar subordinado à hierarquia e políticas organizacionais; ter o seu status, formação e background profissional conhecidos, entre outros, está mais suscetível a cobranças, desconfianças e retaliações, sem falar que os resultados obtidos refletem diretamente na sua credibilidade e confiança junto aos clientes e, em alguns casos, na possibilidade de ficar ou não na organização.

Para que o consultor seja legitimado pelo cliente, sendo percebido como um membro da organização $e$ não como alguém para resolver problemas operacionais, é importante que fique claro o seu papel diferenciado e seja reconhecida a contribuição que ele pode dar aos processos de mudança nas organizações, é necessário que ele esteja capacitado para aproveitar as oportunidades e intervir sempre que necessário.

Essa capacitação, contudo, não pode se restringir a conhecimentos técnicos. Competências interpessoais e de consultoria devem ser desenvolvidas, de forma que o consultor interno esteja certo de que o seu papel como interveniente é ajudar o cliente a ser mais competente e eficaz, criando um ambiente que favoreça o respeito, a confiança $e$ a sinceridade, permita abertura para tratar os conflitos e estimule a participação do cliente nas ações.

Este ensaio, além de contribuir para uma maior compreensão do que seja consultoria interna, chama a atenção - à luz da obra de Argyris - para a necessidade de, ao ser inserido nessa nova atividade, o consultor interno voltar-se para o estudo da intervenção e de suas implicações para a autonomia e o desenvolvimento do sistema-cliente (assim como para o seu próprio desenvolvimento e autonomia). 
O trabalho de Argyris pode ajudar o consultor interno a se preparar melhor para essa atividade, preocupando-se, inclusive, em buscar, mais do que soluções imediatistas, soluções consistentes e duradouras; e a integrar no seu trabalho junto à organização

[...] as tarefas administrativas com os fatores humanos relevantes, comprometendo assim as mentes e os espíritos dos participantes com o propósito de uma ação mais eficaz (ARGYRIS, 2005, p. 137).

O presente ensaio abre possibilidades para futuros estudos relacionados à prática da consultoria interna, tais como: a investigação em empresas que adotam essa modalidade de consultoria, com o objetivo de identificar como o consultor interno tem lidado com os conflitos e ambiguidades próprias de sua atividade, as estratégias utilizadas e sua eficácia; avaliação das estratégias utilizadas pelas empresas para a formação dos consultores internos, entre outros.

\title{
Internal Consulting: being inspired in Argyris for a more efficient action
}

\begin{abstract}
The internal consulting appeared from the necessity of the organizations of keeping in permanent process of renewal and it has been detached in the last decades for its paper in the processes of organizacional change. Its practical is based on the principles of the external consulting and it develops under a climate of conflicts, pressures and psychological consuming equal, if not superior, to that observed in the external consulting. From the analysis of three books of Chris Argyris: Intervention theory and method: the behavioral science view (1970), Theory in Practice: increasing professional effectiveness (1974), and Bad advice, a managemental trap (2005), this theoretical assay search to detach valuable contributions that can help the internal consultant to surpass the conflicts that characterize its activity and to have a more efficient action, creating an environment that favors the respect, the confidence, the participation and the sincerity, conditions to generate greater autonomy of the customer.
\end{abstract}

Key-words: Internal consulting. Consulting skills. 


\section{Referências}

ARGYRIS, Chris. Intervention theory and method: a behavioral science view. Reading Mass: Addison-Wesley Publishing, 1970.

Maus conselhos: uma armadilha gerencial: como distinguir os conselhos eficazes daqueles que não têm valor. Porto Alegre, Bookman, 2005.

ARGYRIS, Chris; SCHÖN, Donald A. Theory in practice: increasing professional effectiveness. São Francisco: Jossey-Bass, 1974.

BLOCK, Peter. Consultoria o desafio da liberdade: Coragem, confiança, parceria e implementação de qualidade em todas as decisões. São Paulo:

Makron, Mcgraw-Hill, 1991.

DEWEY, John. Experiência e educação. 2. ed. São Paulo: Ed. Nacional, 1976.

DONADONE, Júlio César. O mercado internacional de consultorias nas últimas décadas: crescimento, diversificação e formas de disputa. Caderno de Pesquisas em Administração, São Paulo, v. 10, n. 2, p. 1-15, jun. 2003. Trimestral. Disponível em: < www.ead.fea.usp.br/cad-pesq/index.htm >. Acesso em: 24 maio 2006.

A difusão de conceitos gerenciais, imprensa de negócios e o mercado de consultoria nos anos 90. Revista Eletrônica de Gestão

Organizacional, Recife, v. 3, n. 1, p.26-38, abr. 2005. Quadrimestral. Disponível em: <www.gestaoorg.dca.ufpe.br>. Acesso em: 24 maio 2006.

ELTZ, Fábio; VEIT, Mara. Consultoria interna. Salvador: Casa da Qualidade, 1999.

GEBELEIN, Susan H. Profile of an internal consultant: roles and skills for building client confidence. Training and Development Journal, v. 43, n. 3, p. 52-58, março. 1989. Disponível em: <www.proquest.com>. Acesso em: 13 nov. 2006.

GONÇALVES, Marilson Alves. Consultoria. RAE - Revista de Administração de Empresas, São Paulo, v. 31, n. 2, p. 91-98, abr/jun. 1991. Disponível em: < www.rae.com.br >. Acesso em: 24 maio 2006. 
HIEBERT, Murray; OLTHUIS, Ron. Internal consulting. Executive

Excellence, v. 12, n. 4, abr. 1995. p. 16-17. Disponível em:

<www.proquest.com >. Acesso em: 22 fev. 2007.

HUFFINGTON, Clare; BRUNNING, Halina. Internal consultancy in the public sector: case studies. London: Karnac Books, 1994.

JOHRI, H. P; COOPER, J. Chris; PROKOPENKO, J. Managing internal consulting organizations: a new paradigm. Advanced Management Journal, v. 63, n. 4, p. 4-10, Autumn 1998. Disponível em: <www.proquest.com>. Acesso em: 16 nov. 2006.

KELLEY, Robert E. Should you have an internal consultant? Harvard Business Review, v. 57, n. 6, p. 110-120, nov./dez. 1979.

KENTON, Barbara; MOODY, Diane; TAYLOR, Ben. The role of the internal consultant. Roffey Park Institute. 2003. Disponível em: <www.roffeypark.com/ docs/internal consultant.pdf>. Acesso em: 19 mar. 2007.

LACEY, Miriam Y. Internal consulting: perspectives on the process of planned change. Journal of Organizational Change Management. 8, n. 3, p. 7584. 1995. Disponível em: <www.proquest.com>. Acesso em: 16 nov. 2006.

MANCIA, Lídia T. S. Os desafios do modelo de consultoria interna: uma experiência gaúcha. 1997. 184 f. Dissertação (Mestrado) - Curso de Administração, DCA/UFRGS, Porto Alegre, 1997.

Os desafios do Modelo de consultoria interna em recursos humanos. In: BITTENCOURT, Cláudia. Gestão contemporânea de pessoas: novas práticas, conceitos tradicionais. Porto Alegre: Bookman, 2004. p. 144-159.

MOURA, Guilherme Lima. Relações de conhecimento consultor organizacional - cliente à luz da Biologia do Conhecer: uma reinterpretação para desfazer mal-entendidos correntes. 2005. 132 f. Dissertação (Mestrado) - Curso de Administração, DCA/UFPE, Recife, 2005.

ORLICKAS, Elizena. Consultoria interna de recursos humanos. 4. ed. São Paulo: Makron Books, 1999.

WOOD JR, Thomaz; CALDAS, Miguel P. Rindo do que? Como consultores reagem ao humor crítico e à ironia sobre sua profissão. Revista Organização \& Sociedade, Salvador, v. 12, n. 34, p. 83 - 101, jul./set., 2005. Trimestral. 
Ana Lúcia Neves de Moura • Marcos Gilson Gomes Feitosa • Bruno Campello de Souza

WOOD JR, Thomaz; PAULA, Ana Paula Paes de. Empresas de consultoria no Brasil: um estudo múltiplo de casos. In: Encontro da ANPAD, 28, 2004, Curitiba. (Rio de Janeiro): ANPAD, 2004, p. 1-16. CD-ROM.

WOOLDRIDGE, Adrian. The Advice business. The Economist, 23 março 1997. Semanal. Disponível em: <www.economist.com/surveys/ showsurvey.cfm?issue $=19970322>$. Acesso em: 24 maio 2006 . 